\title{
BALANCE OF PLANT OPTIONS FOR THE HEATPIPE BIMODAL SYSTEM
}

\author{
Marc Berte \\ Massachusetts Institute of Technology \\ Nuclear Engineering Dept. \\ Cambridge MA 02139 \\ (617) 253-3801
}

\author{
Brent Capell \\ University of Michigan \\ Nuclear Engineering Dept. \\ Ann Arbor, MI 48109 \\ (313) $764-4260$
}

\begin{abstract}
The Heat pipe Power System (HPS) is a near-tern, low-cost space fission power system with the potential for various balance of plant options. The following options have been studied: a low power thermoelectric design (14kWe output), a small Brayton Cycle system (60-75kWe), and a large Brayton Cycle system (250kWe). These systems were analyzed on a preliminary basis, including mass, volume and structure calculations. This analysis has shown that the HPS system can provide power outputs between $10-250 \mathrm{kWe}$ with specific powers of $\sim 14 \mathrm{~W} / \mathrm{kg}$ for a $14 \mathrm{kWe}$ model to $\sim 100 \mathrm{~W} / \mathrm{kg}$ for a $250 \mathrm{kWe}$ model. The system designs considered in this study utilize a common component base to permit easy expansion and development.
\end{abstract}

\section{INTRODUCTION}

The recent design of the HPS heat pipe-cooled space reactor system provides a potential for a significant increase in the number of missions available for near-term space fission power, as it is both safe, cheap and expandable. The key to developing this near-term solution is the development of a variety of balance of plant options to suit a wide mission base, especially the design of various power conversion systems (PCS) to be utilized with the reactor. For each option, the design must include the primary heat transport system (transports heat from the reactor core to the PCS), the PCS itself, the heat rejection device (radiator), and the various support systems (power regulation, reactor control, etc.).

In this preliminary study, the following systems were analyzed: a $14 \mathrm{kWe}$ thermoelectric design, a $60-75 \mathrm{kWe}$ Brayton Cycle system, and a $250 \mathrm{kWe}$ Brayton Cycle system. During this analysis, a graphite fiber composite radiator was designed and incorporated within these systems. This radiator is designed to have a lower specific mass (mass/unit area) than competing radiator designs, while retaining ease of assembly and testing.

\section{HPS Reactor}

The HPS reactor itself is a modular system that uses heat pipes to transport thermal energy to an external power system at up to $1500 \mathrm{~K}$. This reactor is unique among space reactor concepts because of its expandability and reliability. The HPS reactor is expandable through its use of repeated fuel/heat pipe modules (3-6 fuel pins and a single heat pipe) The reactor can utilize a variety of materials to fit different missions without significantly affecting the design. Expandability is also achieved by simply adding more fuel pin/heat pipe modules to a reactor design, or by reducing the radial size of the fuel pins and heat pipes (thus improving their thermal transfer claracteristics). For this study, two HPS options were utilized as baseline reactors - the HPS7O and the HPS12O (200kWt and $1000 \mathrm{kWt}$, respectively). Both reactor options utilize $\mathrm{UO}_{2}$ fuel (in varying enrichments and total densities) and a Mo (Mo-41Re for the HPS12O) cladding. The heat pipes are also Mo / Mo-41Re (minimizing brazing concerns) and utilize $\mathrm{Li}$ as a working fluid (Poston 1996)

TABLE 1. HPS Reactor Specifications (Poston 1996).

\begin{tabular}{|c|c|c|c|c|c|c|c|}
\hline $\begin{array}{c}\text { Option } \\
\text { Name }\end{array}$ & $\begin{array}{c}\text { Power } \\
(\mathrm{kWt})\end{array}$ & $\begin{array}{c}\text { No. of } \\
\text { Modules }\end{array}$ & $\begin{array}{c}\text { Enrich./ } \\
\text { T.D. }\end{array}$ & $\begin{array}{c}\text { Pin. Dia. } \\
(\mathrm{m})\end{array}$ & $\begin{array}{c}\text { Core } \\
\text { Width }(\mathrm{m})\end{array}$ & $\begin{array}{c}\text { Act. Height } \\
(\mathrm{m})\end{array}$ & $\begin{array}{c}\text { Reactor } \\
\text { Mass }(\mathrm{kg})\end{array}$ \\
\hline HPS70 & 200 & 30 & $97 / 92$ & 0.018 & 0.236 & 0.36 & 325 \\
\hline HPS12O & 1000 & 121 & $97 / 85$ & 0.014 & 0.305 & 0.42 & 480 \\
\hline
\end{tabular}




\section{Primary Heat Transport}

In each of the options the primary heat transport mechanism is the extension of the reactor heat pipes outside of the reactor itself. These primary heat pipes are then brazed to a series of secondary heat pipes (same material and working fluid) which transport the reactor heat to the power conversion system. The primary to secondary heat pipe interface is designed for redundancy and reliability in a micrometeroid environment. Each interface module consists of one primary heat pipe, two secondary heat pipes and a "tri-cusp" to increase heat transfer area.

Each of the secondary heat pipes is rated at the full load of the primary heat pipe. The two to one redundancy provides a type of "sacrificial armor" for the primary heat pipe.

It is important to minimize the temperature drop of this interface, as iti is necessary to keep the input temperature to the PCs as high as possible. Assuming a $0.40 \mathrm{~m}$ interface the maximum temperature drop from the primary to the secondary heat pipe can be reduced to less than $25 \mathrm{~K}$. However, if larger temperature drops are acceptable, a shorter interface section can be used.

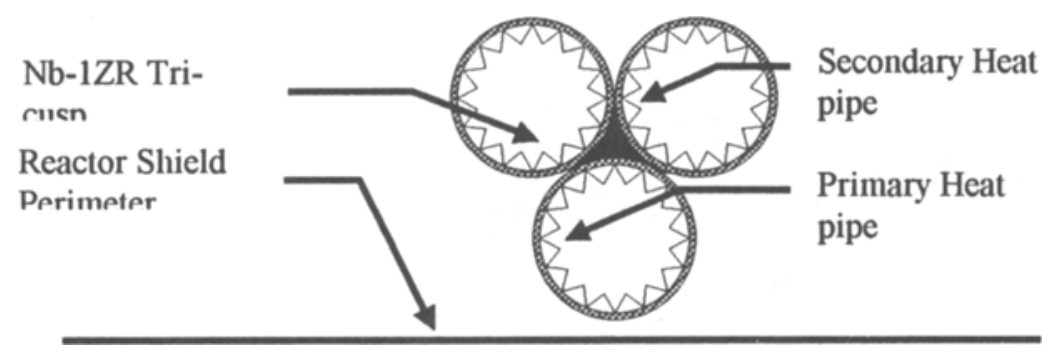

FIGURE 1. Primary/Secondary Heat pipe Interface.

If necessary, this interface can be eliminated to conserve mass (i.e. having the primary heat pipes extend to the PCS). However, eliminating this interface will increase manufacturing complexity since each primary heat pipe has to be built with the module on one end and the power conversion equipment on the other. With the elimination of this interface, the primary heat pipes will also need to be armored to prevent micrometeroid punctures, which offsets the mass lost by eliminating the interface.

This interface can also be eliminated, again at the expense of increasing the manufacturing complexity of the system, by constructing the heat pipes in non-circular shapes (e.g. two D-shaped secondary heat pipes brazed on two faces of a triangular shaped secondary heat pipes).

\section{POWER CONVERSION SYSTEMS}

The three options differ primarily in the power conversion system used. The first option utilizes a low power thermoelectric (TE) power conversion system. This system utilizes an array of TE modules, each with its own small radiator panel. These radiator panels are distributed around a frustum-cylinder radiator arrangement, utilizing the secondary heat pipes as stringers (additional structure is attached on the underside of the radiator. Each of these modules operates at a hot shoe temperature of $1250 \mathrm{~K}$ and a cold shoe temp of $600 \mathrm{~K}$. The radiating surfaces for these modules are small panels of graphite composite bonded to the cold pads of the thermoelectrics. Each module operates at an efficiency of $>7 \%\left(\mathrm{Z}>0.6 \mathrm{e}-3 \mathrm{~K}^{-1}\right)$ and generates $\sim 4.2 \mathrm{~W}$ of electricity while radiating $\sim 60 \mathrm{~W}$ of thermal power. 


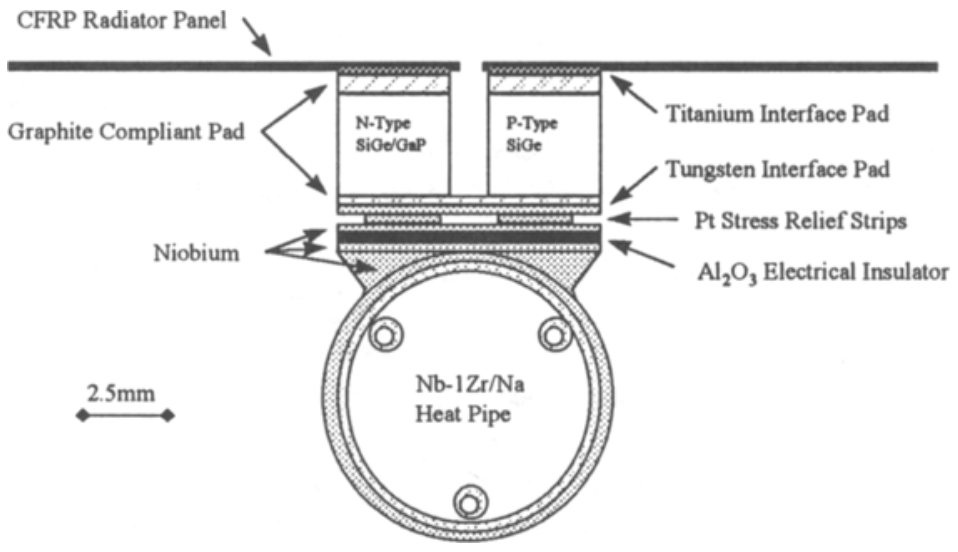

FIGURE 2. Thermoelectric module (Raag 1995).

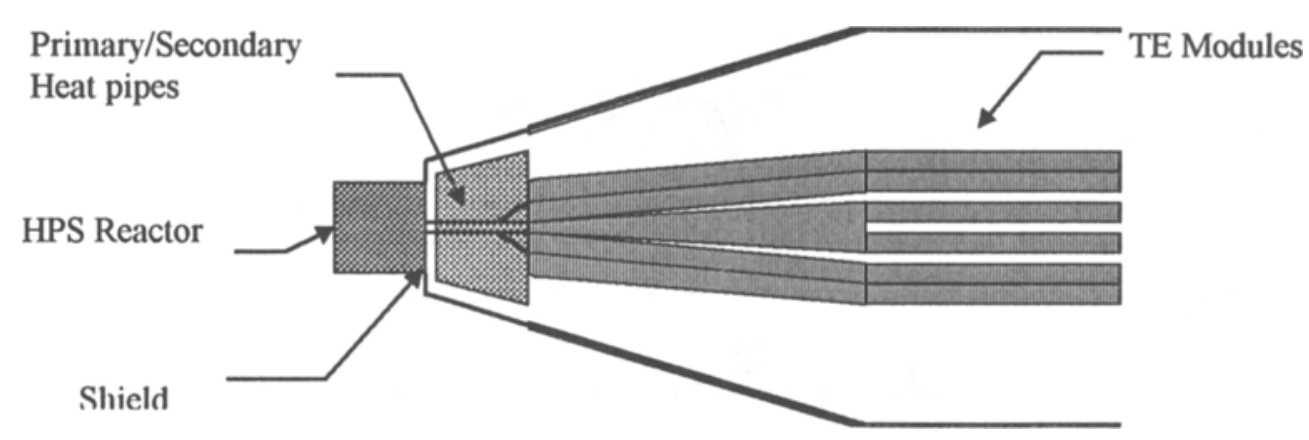

FIGURE 3. HPS-Thermoelectric Modules and Radiator.

The TE-PCS option uses the $200 \mathrm{kWt}$ HPS7O core. This core has 30 primary heat pipes; therefore 60 strips of TE modules in the radiator.

This TE system is assumed as a baseline for this reactor. All of the components are conservatively designedThe figure of merit of $0.6 \mathrm{e}-3 \mathrm{~K}^{-1}$ has already been achieve, composites of this type are readily available (see ACR section), and TE modules of this type have shown operational lives of decades (Ranken et al. 1990).

TABLE 2. Preliminary 14kWe TE Masses.

\begin{tabular}{|l|l|}
\hline Component & Mass (kg) \\
\hline HPS7O & 350 \\
\hline Shield & 150 \\
\hline Primary Heat Transport & 50 \\
\hline $\begin{array}{c}\text { PCS (inc. secondary } \\
\text { heat pipes) }\end{array}$ & 200 \\
\hline Radiator panels & 50 \\
\hline Support components & 250 \\
\hline Total & $\mathbf{1 0 0 0 k g}$ \\
\hline
\end{tabular}

\section{Small Brayton Cycle PCS Option}

The second PCS option for the HPS system is a small $(60-75 \mathrm{kWe})$ closed Brayton cycle. This system uses the same HPS core as the thermoelectric option, but with a higher thermodynamic efficiency $(\sim 30 \%$ in this temperature range) The baseline design for this system uses two $75 \mathrm{kWe}$ TAC (turbine-alternator-compressor) sets. 
Each of these sets incorporates its own hot and cold heat exchangers, recuperators, and control hardware. The system breakdown is as follows:

TABLE 3. Preliminary 75kWe CBC Masses.

\begin{tabular}{|l|l|}
\hline Component & Mass (kg) \\
\hline HPS7O & 350 \\
\hline Shield & 150 \\
\hline Primary Heat Transport & 50 \\
\hline PCS & 700 \\
\hline Radiator & 250 \\
\hline Support components & 250 \\
\hline Total & $\mathbf{1 7 5 0 k g}$ \\
\hline
\end{tabular}

This is a highly conservative baseline mass estimate; The masses of the PCS are derived from the total system mass of the AlliedSignal Turbogenerator ${ }^{\mathrm{TM}}$ series $75 \mathrm{kWe}$ turbogenerators (quoted figure $10-12 \mathrm{lbs} / \mathrm{kWe}$ ) (AlliedSignal 1997). In the space version, many components of this system will have lower masses from lighter materials and designs.

The radiator system for this system operates at a much lower temperature than the TE option's radiator panels $(450 \mathrm{~K}$ vs. $575 \mathrm{~K})$ thus the radiator is almost twice as large. The PCS is not incorporated within the radiator; thus more options are available for the CBC radiator. For this system, the radiator designed uses water heat pipes to disperse the heat from the cold-side heat exchanger to the radiating area. These heat pipes can easily incorporate flexible bellows to allow the radiator to deploy out from a compact launch configuration.

\section{Larue Brayton Cycle PCS Option}

This PCS option provides a lightweight and extremely high power system for use where a compact power source is needed (e.g. nuclear electric propulsion missions). This design utilizes the HPS12O reactor (1MWt) with a CBC power conversion system to generate $250 \mathrm{kWe}$ for a goal total system mass of $2500 \mathrm{~kg}$. The radiator system for this power output is far larger than the simple radiator proposed for the small-CBC system. In the case of the large CBC option, the area needed for the radiator is larger than can be packaged within a reasonable launch package without excessive heat pipe bending; therefore an alternate radiator was designed. The cold side heat exchanger of the CBC system will transfer heat to a circulating liquid (rather than directly to the radiator heat pipes). This fluid will then travel through the base of each folded radiator panel, transferring heat to a series of heat pipes that will disperse the heat throughout the radiator area. This system requires some amount of armor for the liquid loops (to augment the safety provided by their redundancy) and has a greater temperature drop from the cold side heat exchanger to the radiator, the ability to package this radiator in a relatively small space (by reducing the difficulty in folding the thermal transport devices) outweighs the slight loss in efficiency.

TABLE 4. Preliminary 250kWe CBC Masses.
\begin{tabular}{|l|l|}
\hline Component & Mass (kg) \\
\hline HPS12O & 480 \\
\hline Shield & 320 \\
\hline $\begin{array}{l}\text { Primary Heat } \\
\text { Transport }\end{array}$ & 100 \\
\hline PCS & 700 \\
\hline Radiator & 600 \\
\hline Support components & 400 \\
\hline Total & $\mathbf{2 5 0 0 k g}$ \\
\hline
\end{tabular}

One primary use for this large CBC system is the supply of power for Nuclear Electric Propulsion (NEP) spacecraft. 


\section{Advanced Composite Radiator}

The advanced composite radiator is a preliminary point design for a composite radiator panel utilizing high conductivity graphite fibers to both minimize the mass of a deployed radiator panel and reduce the temperature drops across the radiator. The panel designed for these systems utilizes composite face sheets constructed of high conductivity carbon fibers in a multi-ply laminate, with the majority of the plies in the direction perpendicular to the heat generating elements (thermoelectric modules or heat pipes). In the case of the heat pipe radiators (associated with the CBC options) the radiator is double sided with a honeycomb core between the face sheets to provide dimensional stability. The heat pipes are imbedded within this core region during fabrication.

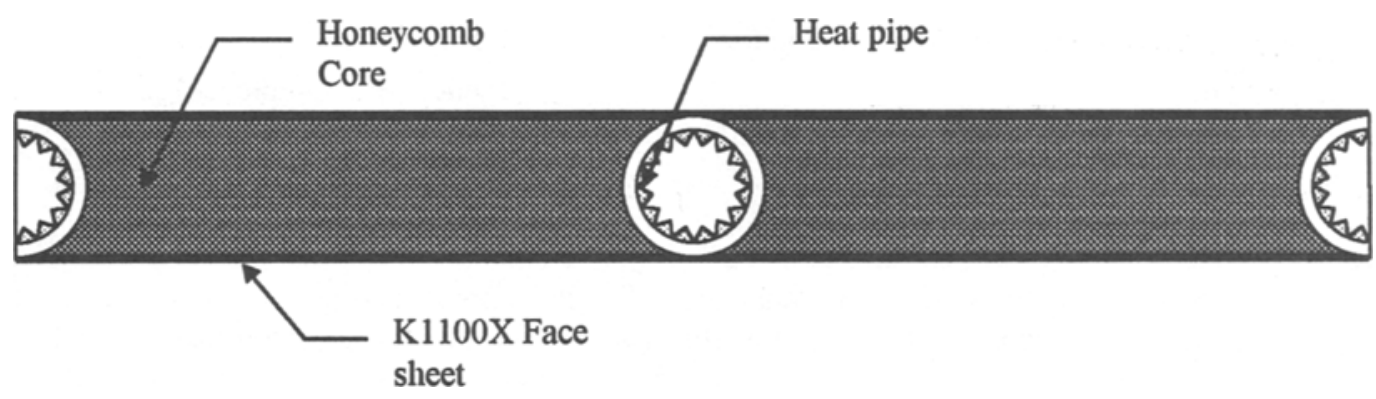

FIGURE 4. Advanced Composite Radiator with Heat Pipes.

This radiator provides advantages over pumped loop aluminum heat exchangers (Shuttle Radiator) and CarbonCarbon heat exchangers as it is both safer (because of the many TE modules or heat pipes) and extremely easy to fabricate (Byrens 1997).

\section{Support Systems}

The support systems for these options can be broken down into two primary categories, power support and structural support. The power support systems include the computer and data bus for reactor and power system control, the power regulators and primary bus (derived from international space station components), and the instrumentation necessary to maintain system health. The structural components are primarily the support struts for the PCS and the reactor/shield module and the deployable boom (used to increase separation between payload and the reactor system), such as the telescopic boom developed by Astro Aerospace Inc. This boom is stiffer than the standard deployable booms (such as truss-style booms), yet still has a low mass $(<80 \mathrm{~kg}$ for $10 \mathrm{~m}$ boom) (Edwards 1997).

\section{FUTURE OPTIONS}

Because of the modular design of the HPS system, as well as the directability of the thermal output (the heat pipes can be incorporated into heat exchangers, boilers, TE modules, etc.) there exist further options for the HPS balance of plant. The options that are currently being considered for future study/use are AMTEC conversion (the heat pipes can easily be incorporated into AMTEC cells), Rankine Cycle (the HPS heat pipes provide the thermal flux necessary to construct an efficient boiler), and forced-gas radiator cooling for Martian surface applications.

\section{CONCLUSION}

The HPS power system has a potential for various balance of plant options to fit a variety of mission requirements. These point designs have been studied: a $14 \mathrm{kWe}$ thermoelectric design, a $60-75 \mathrm{kWe}$ Brayton Cycle 
$250 \mathrm{kWe}$ Brayton Cycle system. These systems were analyzed on a preliminary basis, including mass, volume and structure calculations. This analysis has shown that the HPS system can provide power outputs between 10-250 $\mathrm{kWe}$ with specific powers of $\sim 14 \mathrm{~W} / \mathrm{kg}$ for a $14 \mathrm{kWe}$ model to $\sim 100 \mathrm{~W} / \mathrm{kg}$ for a $250 \mathrm{kWe}$ model. The HPS system also has the versatility necessary to provide power through the use of other possible conversion systems (such as Rankine systems or AMTEC). These options will be studied in future work.

\section{Acknowledgments}

This paper was a summary of work done for the Nuclear Systems Design and Analysis group at Los Alamos National Laboratory

\section{References}

AlliedSignal Sales Brochure: Turbogenerator Systems (1997) Allied Signal Turbogenerator Systems, Torrance, CA.

Byrens, R. (1997) Fiberite, Orange, CA, personal communication, August 1997.

Edwards, K. (1997) Astro Aerospace, Cupertina, CA, personal communication, August 1997.

Poston, D.I. and M.G. Houts (1996) "Nuclear and Thermal Analysis of the Heatpipe Power and Bimodal Systems," in Proceedings of Space Technology \& Applications International Forum (STAIF-96), DOE CONF960109, M.S. El-Genk ed., American Institute of Physics, AIP CP 361, Albuquerque, New Mexico, 3:1083-1093.

Raag, V. (1995) Thermotrex, Waltham, MA, personal communication, August 1995.

Ranken, W.A., P.J. Drivas, and V. Raag (1990) "Low Risk Low Power Heat Pipe/Thermoelectric Space Power Supply," in Proceedings of the 7 th Symposium on Space Nuclear Power and Propulsion, M.S. El-Genk ed., University of New Mexico's ISNPS, Albuquerque, New Mexico, 1:488-496. 